\title{
Clinical Experience With Angiotensin II Receptor Antagonists
}

Hans R. Brunner, Yves Christen, Alain Munafo, Robert J. Lee, Bernard Waeber, and Jurg Nussberger

This series of studies was designed to assess in normal volunteers the relationships between various doses $(5,10,20,40,80$, and $120 \mathrm{mg})$ of the orally active angiotensin II antagonist losartan (DuP 753, MK-954) and their inhibitory effect on the pressure response to a given bolus of angiotensin I or II. It was found that the maximal inhibitory effect was reached with a dose of $80 \mathrm{mg}$. The minimal dose necessary for maximal efficacy would therefore be expected to be between 40 and $80 \mathrm{mg}$. The effect lasted for more than $24 \mathrm{~h}$ and was related almost exclusively to the circulating levels of the active metabolite EXP3174. It remains to be demonstrated in hypertensive patients that the same dose relationship holds for the antihypertensive effect, but preliminary data already suggest that this is the case. Am J Hypertens 1992;5:243S - 246S

KeY WORDS: Angiotensin II receptor antagonists, renin-angiotensin system, losartan, DuP 753, antihypertensive agents.
$\mathrm{I}$ nterruption of the renin-angiotensin system (RAS) as a means of controlling hypertension has received a great deal of attention in recent years. The most useful therapeutic agents to evolve from these investigations are the angiotensin converting enzyme (ACE) inhibitors. Captopril ${ }^{1}$ and enalapril, ${ }^{2}$ which were initially introduced for treating severe or renin-dependent hypertension, have been shown to be effective in managing milder forms of essential hypertension in which there is no clear activation of the renin-angiotensin system. This suggests that the renin-angiotensin system plays a broader role in the pathophysiology of hypertension. ${ }^{3}$

While ACE inhibition is effective in controlling blood pressure, this does not occur without some side effects such as cough and angioedema. These side effects are believed to be related to the fact that ACE, which is a relatively nonspecific peptidyl dipeptidase, is involved

From the Hypertension Division, University Hospital Center, Lausanne, Switzerland.

Address correspondence and reprint requests to Hans R. Brunner MD, Division d'Hypertension, Centre Hospitalier Universitaire Vaudois, $\mathrm{CH}-1011$, Lausanne, Switzerland. in the breakdown of bradykinin. Inhibition of ACE thus leads to potentiation of bradykinin actions, which may be responsible for the side effects.

Recently, specific, orally active, nonpeptide angiotensin II (ANG II) receptor antagonists have been developed. ${ }^{4}$ Losartan is the first of these agents to enter clinical trials. The potential advantages of this approach to blocking the renin-angiotensin system are that, by inhibiting the hormone from binding to its receptor, the system can be specifically turned off regardless of the source of ANG II. In addition, since ACE is not affected, there is no potentiation of bradykinin and, therefore, no cough or angioedema would be expected during therapy with losartan.

\section{METHODS}

The initial studies in human subjects assessed the tolerance and inhibitory effect of losartan (DuP 753) on the pressor action of exogenous ANG I or ANG II. In the first study, single oral doses of losartan $(2.5,5,10,20$, and $40 \mathrm{mg}$ ) were studied $v$ placebo. ${ }^{5}$ A dose-response relationship was established with regard to systolic blood pressure responses to increasing intravenous doses of ANG (I or II) in each subject. The test dose of 
ANG I selected was one that increased systolic blood pressure by about $30 \mathrm{~mm} \mathrm{Hg}$. This dose was then used to define the baseline systolic blood pressure response to ANG and became the challenge dose for that subject. The effect of losartan was established by bolus injections of the challenge dose of ANG given from $15 \mathrm{~min}$ to $27 \mathrm{~h}$ after ingestion of losartan (dissolved in $20 \mathrm{~mL}$ of tap water).

\section{RESULTS}

Losartan had no effect on resting blood pressure or heart rate and was well-tolerated in this study. Doses of 2.5 and $5 \mathrm{mg}$ of losartan had no effect on systolic blood pressure response to ANG I when compared with placebo. Doses of 10, 20, and $40 \mathrm{mg}$ of losartan produced a dose-related inhibition of the systolic blood pressure response to ANG I (Figure 1), which was accompanied by increases in plasma ANG II. Plasma aldosterone levels fell after the administration of losartan, but these changes were not different from placebo (Figure 2).

From Figure 1 it is evident that the duration of the ANG I-blocking effect of losartan is prolonged, up to 24 $\mathrm{h}$ or more at the $40 \mathrm{mg}$ dose. Figure 3 compares the time course of the mean plasma levels of losartan with the levels of immunoreactive ANG II and with the inhibition of the systolic blood pressure response to ANG I after single oral doses of 20 and $40 \mathrm{mg}$ losartan. It is clear that the effects on systolic blood pressure and immunoreactive ANG II persist long after plasma levels of losar$\tan$ have disappeared. The prolonged effects of the drug are due to the presence of the active metabolite E-3174, which has a half-life of approximately $6.5 \mathrm{~h}$.

The second study of losartan in human subjects was a multiple-dose tolerance study, which also assessed the inhibitory effects of repeated dosing with losartan on the response of systolic blood pressure to ANG II. ${ }^{6}$ The doses of losartan studied were $5,10,20$, or $40 \mathrm{mg}$, given orally once a day for 8 days. These doses were compared

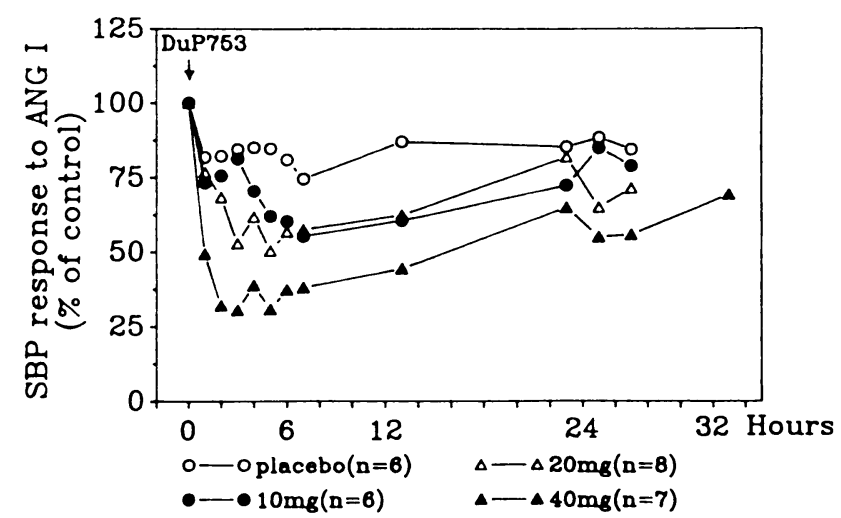

FIGURE 1. Plots of effects of single doses of oral DuP 753 (10, 20 , or $40 \mathrm{mg}$ ) or placebo on systolic blood pressure (SBP) response (mean) to test doses of angiotensin I (ANG I) in healthy volunteers.

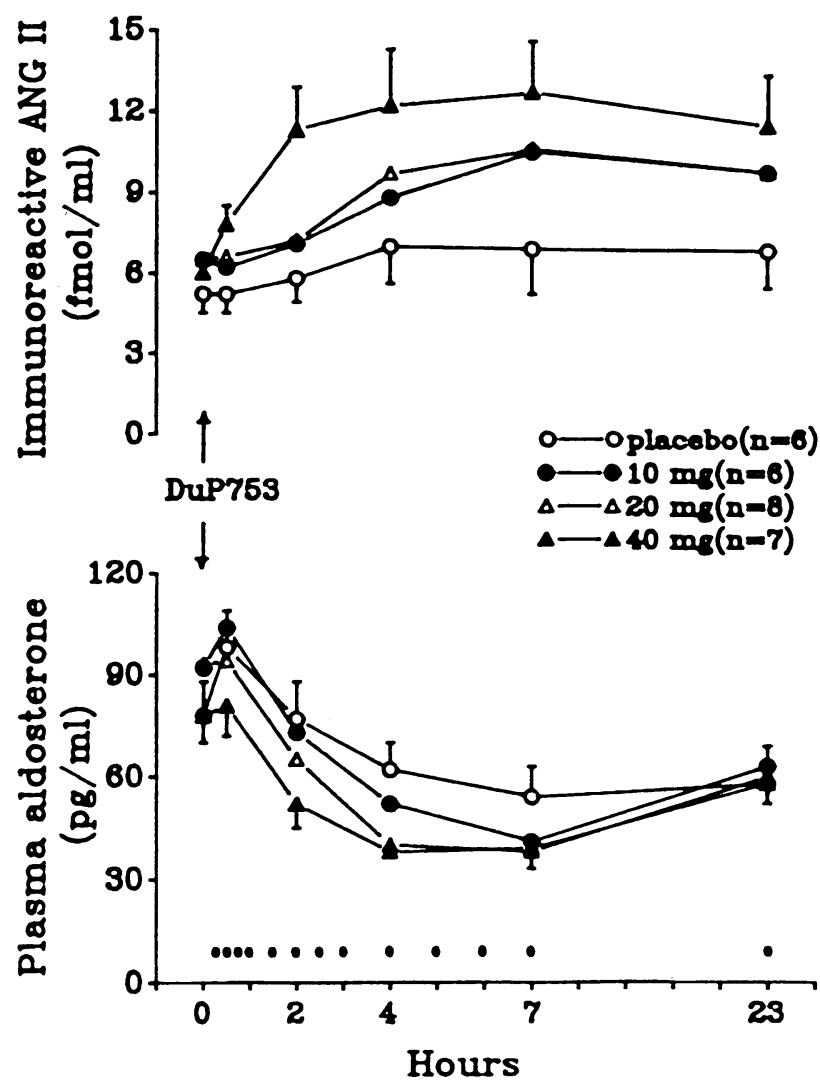

FIGURE 2. Effects of single doses of oral DuP $753(10,20$, or 40 $\mathrm{mg}$ ) or placebo on plasma aldosterone (lower panel) and immunoreactive angiotensin II (ANG II) (upper panel). Bullets on abscissa, ANG I test-dose injections. Values are given as mean \pm SEM.

with placebo given for 8 days. This study was carried out in a similar fashion to the single-dose study, in that dose-response relationships were established with regard to the systolic blood pressure response to exogenous ANG II. The challenge dose was again targeted to cause an approximately $30 \mathrm{~mm} \mathrm{Hg}$ increase in systolic blood pressure. The ANG II challenge was carried out on days 2, 4, and 8 before and 6 and $12 \mathrm{~h}$ following ingestion of losartan or placebo. Additional challenges were performed $24 \mathrm{~h}$ before adminstration of the drug on day 1 , and at 24,30 , and $36 \mathrm{~h}$ after the last dose on day 8.

Losartan was well-tolerated in this study, with no clinically significant side effects observed after multiple dosing. As in the first study, losartan had no effect on resting blood pressure or heart rate.

Losartan (10 to $40 \mathrm{mg}$ ) caused a dose-dependent decrease in the systolic blood pressure response to ANG II throughout the treatment period, when compared with placebo. The degree of blockade achieved with the 20 and $40 \mathrm{mg}$ doses was similar $6 \mathrm{~h}$ after drug intake on 

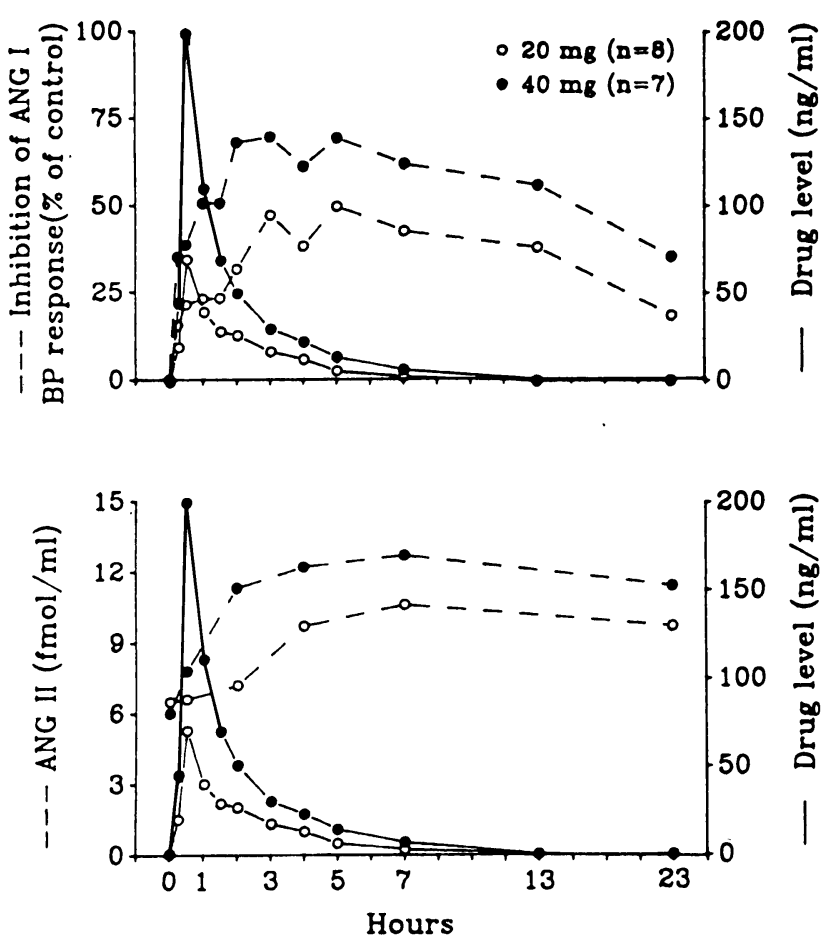

FIGURE 3. Comparisons of DuP 753 plasma levels (mean) with inhibition of systolic blood pressure (BP) response to test doses of angiotensin I (ANG I) (upper panel) and immunoreactive ANG II (lower panel) after single oral doses of DuP 753 (20 and $40 \mathrm{mg}$ ).

days 1,4 , and $8(P<.01)$ compared with placebo. On days 4 and 8 , subjects receiving $40 \mathrm{mg}$ losartan showed a clear trend toward a reduced response to ANG II immediately before the morning dose of the drug (Figure 4). At peak effect, the $40 \mathrm{mg}$ doses of losartan caused an approximately $70 \%$ reduction in the systolic blood pressure response to ANG II.

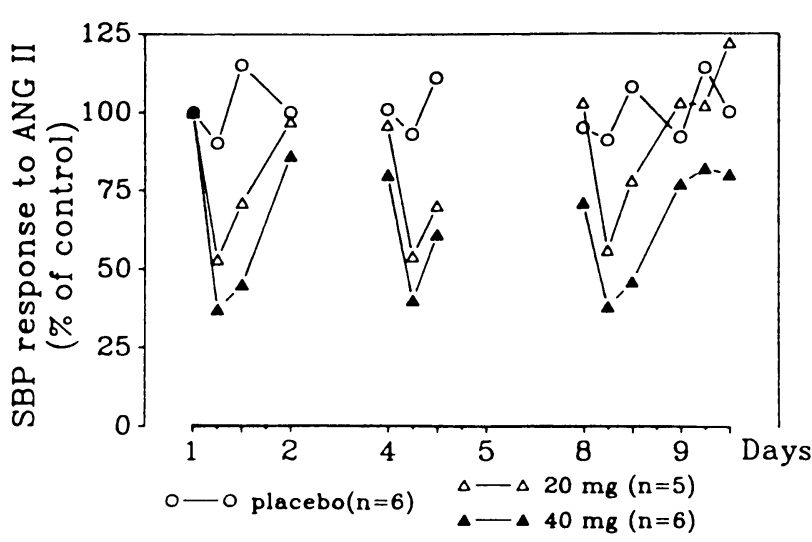

FIGURE 4. Plots of effects of 8 consecutive days of treatment with two oral doses of either DuP $753(20$ or $40 \mathrm{mg}$ ) or placebo on systolic blood pressure $(S B P)$ response (mean) to test doses of angiotensin II (ANG II) in healthy volunteers.
Plasma renin activity and ANG II levels also responded with a dose-dependent compensatory rise which was more pronounced on day 8 than on day 1 of drug administration (Figure 5). The long duration of the blocking effect of losartan is reflected in the plasma renin activity and ANG II levels on day 8; these levels were clearly increased prior to the administration of the 20 and $40 \mathrm{mg}$ dose. This prolonged duration of action is undoubtedly due to the presence of the active metabolite of losartan (E-3174).

Subsequently, the effects of 40,80 , and $120 \mathrm{mg}$ oral doses of losartan on systolic blood pressure responses to ANG II were studied in the same fashion. The $80 \mathrm{mg}$ dose produced a maximal blockade of the systolic blood pressure response to ANG II $(>80 \%) .^{6}$ In this study, Munafo and coworkers investigated the relationships between plasma concentrations of losartan; its active metabolite, E-3174; and ANG II blockade in six healthy subjects who received 40,80 , or $120 \mathrm{mg}$ of losartan or placebo at 1 week intervals in a cross-over protocol. E-3174 reached higher plasma concentrations and was eliminated more slowly than losartan; E-3174 plasma levels paralleled the profile of ANG II blockade more closely than did plasma levels of losartan. The inhibition of the blood pressure response was dose-dependent. The concentration-response curve suggested that E-3174 levels higher than about $200 \mathrm{ng} / \mathrm{mL}$ do not further enhance the effect. There was no gain in either the degree or the duration of inhibition from increasing the oral dose of losartan beyond $80 \mathrm{mg}$.

The reactive increase in plasma renin activity and circulating ANG II in these normotensive subjects was highly variable and could not be used to predict the inhibition in individual subjects. The researchers concluded that the effect of losartan is most likely attributable to the long-acting metabolite E-3174.

\section{DISCUSSION}

The results of these studies led to the expectation that the effective antihypertensive dose of losartan would be between 40 and $80 \mathrm{mg}$ and would have a duration of effect that would support a once-daily dose regimen. Nelson and coworkers ${ }^{7}$ have reported the antihypertensive effects of losartan $(50,100$, or $150 \mathrm{mg}$ taken orally once daily) compared with placebo and $10 \mathrm{mg}$ enalapril taken orally once daily in 98 mildly to moderately hypertensive patients. After 5 days of dosing, a significant decrease in both systolic and diastolic blood pressure was seen when compared with placebo. There was no difference in the magnitude of response between the three doses of losartan or the $10 \mathrm{mg}$ dose of enalapril. It would appear that the losartan doses studied are at the high end of the dose-response curve, since 100 and 150 $\mathrm{mg}$ doses had no additional effect on blood pressure. 
FIGURE 5. Effects of four different daily oral doses of DuP $753(5,10,20$, or $40 \mathrm{mg})$ or placebo $(n=6$ for each dose except dose of $20 \mathrm{mg}$, where $n=5$ ) on plasma renin activity and immunoreactive angiotensin II (ANG II), measured before and $6 \mathrm{~h}$ after drug intake on days 1 and 8 . Values are given as mean \pm standard error of the mean. ${ }^{*} \mathrm{P}<.05 .{ }^{* * \mathrm{P}}<.01 \mathrm{v}$ placebo.
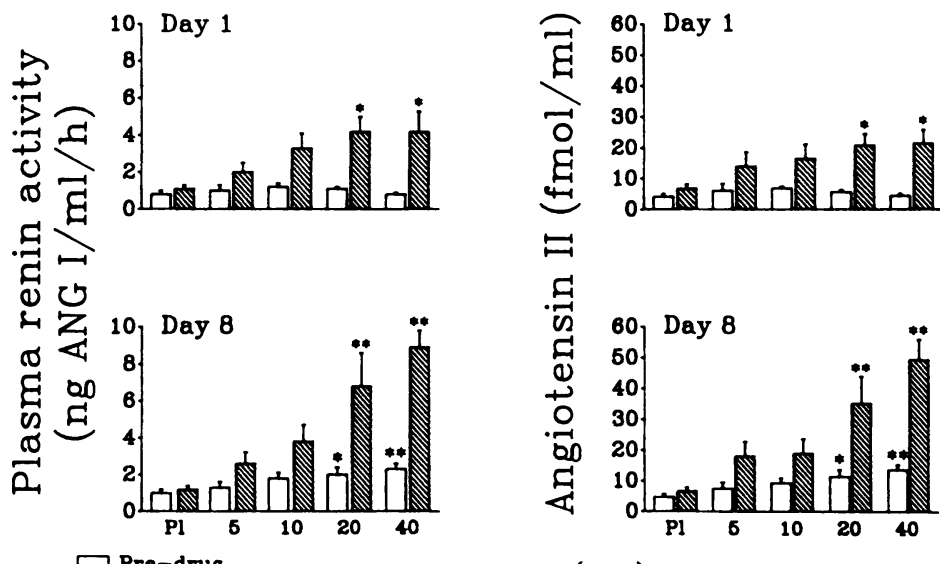

$\square$ Pre-drug
$6 \mathrm{~h}$ post-drug
-

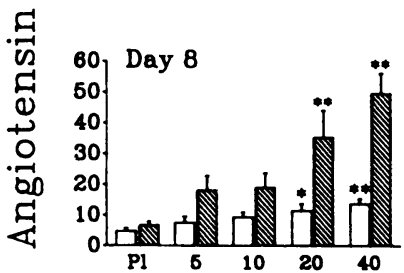

DuP 753 (mg)
Further studies are in progress to define the dose-response relationships of losartan with regard to bloodpressure lowering.

\section{REFERENCES}

1. Ondetti MA, Rubin A, Cushman DW: Design of specific inhibitors of angiotensin converting enzyme: a new class of orally active antihypertensive agents. Science 1977; 196:441-444.

2. Patchett A, Harris E, Tristram E, et al: A new class of angiotensin converting enzyme inhibitors. Nature 1980;260:280-283.

3. Waeber B, Nussberger J, Brunner HR: Angiotensin-converting enzyme inhibitors in hypertension, in Laragh $\mathrm{JH}$, Brenner BM (eds): Hypertension: Pathophysiology, Diagnosis, and Management. New York, Raven Press, 1990, pp 2209-2232.
4. Timmermans PBMWM, Carini DJ, Chin AT, et al: The discovery of a new class of highly specific nonpeptide angiotensin II receptor antagonists. Am J Hypertens 1991;4:275S-281S

5. Christen $Y$, Waeber B, Nussberger J, et al: Oral administration of DuP 753, a specific angiotensin II receptor antagonist, to normal male volunteers. Circulation 1991; 83:1333-1342.

6. Munafo A, Christen Y, Nussberger J, et al: Drug concentration response relationships in normal volunteers after oral administration of losartan (DuP 753, MK 954), an angiotensin II receptor antagonist. Clin Pharmacol Ther 1992;51:513-521.

7. Nelson E, Merrill D, Sweet CS, et al: Efficacy and safety of oral MK-954 (DuP 753), an angiotensin receptor antagonist in essential hypertension (abst). J Hypertens 1991;9 (suppl 6):5468-5469. 